\title{
Simulation and Experimental Studies on Hydrodynamic Deep Drawing of 2198 Aluminum Lithium Alloy
}

\author{
Guo Xunzhong ${ }^{1}, \quad$ Wang Liuan ${ }^{1}, \quad$ Ling Juan ${ }^{2}, \quad$ Ma Fuye ${ }^{1}, \quad$ Tao Jie ${ }^{1}, \quad$ Xu Yong ${ }^{3}$, \\ Jin Kai ${ }^{4}$, Wang Huiting ${ }^{5}$ \\ ${ }^{1}$ Nanjing University of Aeronautics and Astronautics, Nanjing 211106, China; ${ }^{2}$ Special Equipment Safety Supervision Inspection Institute of \\ Jiangsu Province, Nanjing 210036, China; ${ }^{3}$ Institute of Metal Research, Chinese Academy of Sciences, Shenyang 110016, China; \\ ${ }^{4}$ Sogang University, Seoul, 121-742, Korea; ${ }^{5}$ Anhui University of Technology, Maanshan 243002, China
}

\begin{abstract}
The process of hydrodynamic deep drawing of A12198 was investigated by finite element (FE) simulation and experimental works. The effects of die cavity pressure, blank holder gap and pre-bulging pressure on the forming process and the thickness distribution were evaluated. The results indicate that the pressure inside the liquid chamber and the blank holder gap or blank holder force are the main factors affecting hydrodynamic deep drawing process. In addition, appropriate pre-bulging pressure is beneficial to form good quality parts with a relatively uniform wall thickness.
\end{abstract}

Key words: 2198 Al-Li alloy; hydrodynamic deep drawing; numerical simulation; practical forming

The aluminum lithium alloy 2198 is a new type of high-strength structural material. Due to the advantages of low density, high elastic modulus, high specific strength and low fatigue crack growth rate, 2198 aluminum lithium alloy is considered as one of the most competitive light weight and high strength structural materials in the aerospace industry ${ }^{[1-5]}$.

Hydrodynamic deep drawing (HDD) method is widely used in the forming of complex thin-walled parts, especially the aluminum alloy parts in aerospace field owing to its technical advantages of high forming limit, high dimensional precision and good surface quality ${ }^{[6,7]}$. According to this forming technology, the sheet can be attached to the punch under the pressure created by force-transmitting medium, then the parts are fabricated. Under the action of high pressure hydraulic fluid in the liquid chamber, the blank and punch fit tightly to avoid the vacant area of deformation. The flange area of sheet metal shows a good performance of fluid lubrication, to reduce the friction and improve the carrying capacities in the fillet and force-transmitting areas of punch. Fig. 1 shows the process of HDD.
It is possible to meet the actual demands of complex thin-walled parts of large-scale civil aircrafts by adopting the technology of HDD of $2198 \mathrm{Al}-\mathrm{Li}$ alloy. However, during this process, the material deformation and flowing laws are complex. Therefore, the finite element (FE) simulation is needed to analyze the forming process ${ }^{[8,9]}$. But related research on the hydrodynamic deep drawing process of 2198 $\mathrm{Al}-\mathrm{Li}$ alloy has not been reported so far. Furthermore, there is also a serious lack of information on the basic material formability. Therefore, the precision of FE simulation results cannot be ensured ${ }^{[10,11]}$.

The object of the present paper is to study the laws of plastic deformation of $2198 \mathrm{Al}-\mathrm{Li}$ alloy cylindrical parts with oblique plane. The ETA/Dynaform was applied to simulate the process of hydrodynamic deep drawing. Based on the simulation results, $2198 \mathrm{Al}-\mathrm{Li}$ alloy sheet blank was hydroformed. Finally, the simulation and experimental results were compared, to verify the validity of the simulation results.

Fig. 2 shows the engineering drawing of a beveled and cylindrical part which was selected in this paper. The part

$\overline{\text { Received date: July } 25,2016}$

Foundation item: National Nature Science Foundation of China (51205196, 51275003); Natural Science Foundation of Jiangsu Province (BK20151469); the Fundamental Research Funds for the Central Universities (NJ20150023); Priority Academic Program Development of Jiangsu Higher Education Institutions (PAPD)

Corresponding author: Guo Xunzhong, Ph. D., Associate Professor, College of Materials Science and Technology, Nanjing University of Aeronautics and Astronautics, Nanjing 211106, P. R. China, Tel: 0086-25-52112911, E-mail: guoxunzhong@ nuaa.edu.cn 

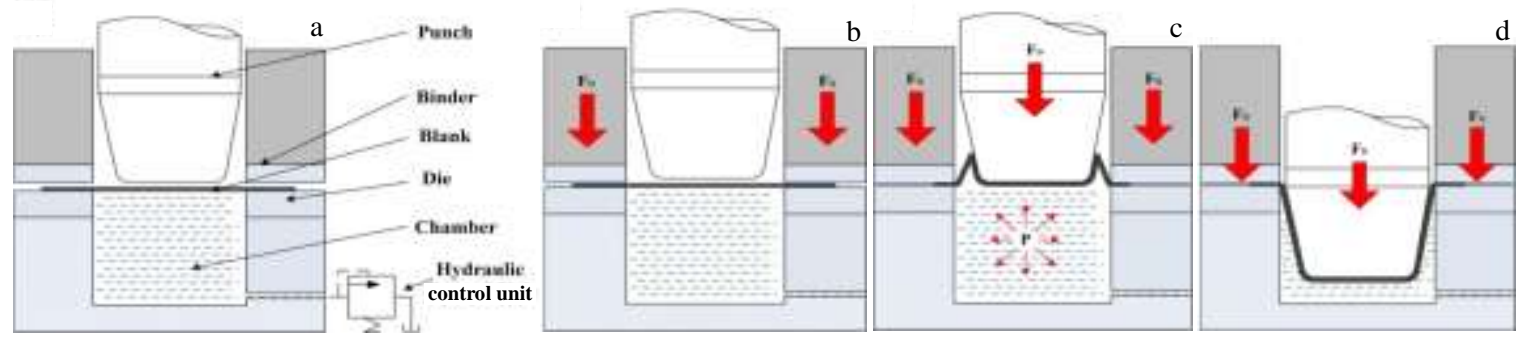

Fig.1 Schematic drawing of hydrodynamic deep drawing process: (a) sheet in position, (b) downward movement of blank holder, (c) downward movement of punch, and (d) end of the sheet forming

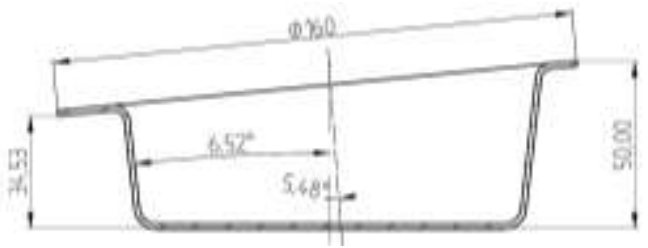

Fig.2 Engineering drawing of beveled and cylindrical component

required high dimensional accuracy and uniform wall thickness. In addition, during the actual forming process, the punch and the sheet were in point contact initially which made the local concentration stress extremely large and thus the part cracked easily.

\section{FE Simulation of Hydrodynamic Deep Drawing Process}

\subsection{Material model}

The constitutive equation $\sigma=\sigma_{y}+K \varepsilon^{n}$ was adopted to fit the stress-strain curve of 2198-T3 aluminum lithium alloy sheet. The mechanical properties of the base sheet metals along the rolling directions of $0^{\circ}, 45^{\circ}$, and $90^{\circ}$ are depicted in Table 1 .

\subsection{FE model}

The thickness of sheet is $1.6 \mathrm{~mm}$, and the diameter is 200 $\mathrm{mm}$. The geometrical models were put into the ETA/ Dynaform software after building them in CAD software, and the module of Sheet Forming was applied to conduct the finite element simulation of sheet hydrodynamic deep drawing and forming. The detailed finite element model is shown in Fig.3.

For the finite element model, the mould was meshed by the rigid body, and then the sheet metal was meshed by the shell element. During the deformation process, the self-adaptive meshing technology was adopted. The feeding distance of punch was $50 \mathrm{~mm}$. The values of friction between the tools and sheet were 0.05 . The Barlat-Lain anisotropic material model was used in the simulation.

\subsection{Finite element simulation results}

1.3.1 Influence of pressure inside the liquid chamber on wall thickness of parts

The appropriate overflowing pressure of liquid from hydrodynamic chamber is one of the key factors that determine the success of hydrodynamic deep drawing process. Due to the action of pressure inside the liquid chamber, the sheet was lifted upwards. Then, the hydraulic oil flowed into

Table 1 Basic formability of Al 2198-T3 sheet

\begin{tabular}{ccccccc}
\hline \multirow{2}{*}{ Orientation $/\left(^{\circ}\right)$} & $\begin{array}{c}\text { Young's modulus, } \\
E / \mathrm{GPa}\end{array}$ & $\begin{array}{c}\text { Percentage elongation } \\
\text { after fracture, } \delta / \%\end{array}$ & $\begin{array}{c}\text { Yield strength, } \\
\sigma_{\mathrm{s}} / \mathrm{MPa}\end{array}$ & $\begin{array}{c}\text { Tensile strength, } \\
\sigma_{\mathrm{s}} / \mathrm{MPa}\end{array}$ & $n$ & $k$ \\
\hline 0 & 80.70 & 18.67 & 295.48 & 399.51 & 0.20 & 691.00 \\
45 & 77.99 & 19.35 & 261.04 & 375.70 & 0.21 & 654.22 \\
90 & 73.08 & 22.06 & 249.68 & 363.11 & 0.20 & 642.07 \\
\hline
\end{tabular}

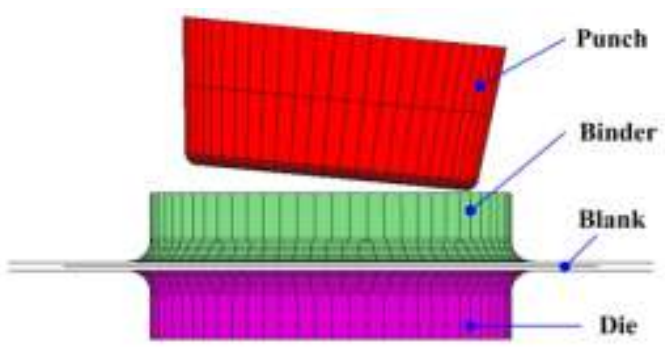

Fig.3 FE model of hydrodynamic deep drawing and forming of 2198 aluminum lithium alloy sheet the gap between the sheet and the die so that the effective lubrication was obtained and the frictional resistance decreased. Furthermore, because of the action of hydraulic pressure, the sheet was closely attached to the punch and the effective "friction conservation effects" was generated between the sheet and the punch, which contributed to the process of hydrodynamic deep drawing sheet. To obtain the reasonable overflowing pressure inside liquid chamber, 10, 15, 20, 25, 30, 40 and $50 \mathrm{MPa}$ were chosen as the overflowing pressures. The hydraulic loading paths are shown in Fig.4. Moreover, the hydraulic pressure was applied on the whole 


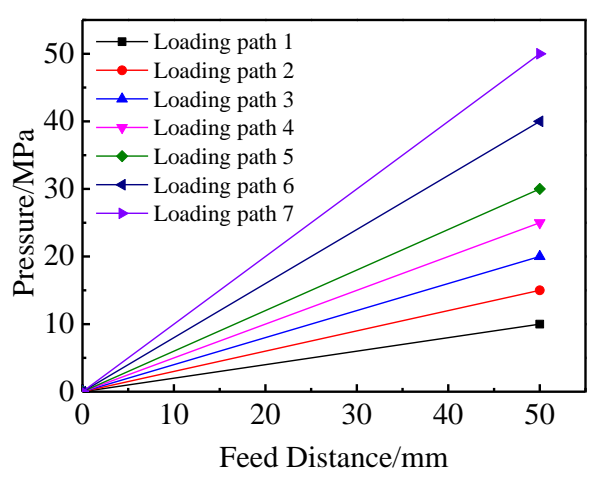

Fig.4 Loading paths of different pressures for hydroforming

sheet, and then the blank holder gap was 1.05 times of the sheet thickness.

The thinning ratios of parts under the different overflowing pressures are shown in Fig.5. The wall thickness of the formed part decreased to minimum when the pressure of liquid chamber was $20 \mathrm{MPa}$. Subsequently, the thinning ratio of wall thickness increased with the overflowing pressure increasing in the liquid chamber. While the pressures of liquid chamber were 20,25 and $30 \mathrm{MPa}$, the thinning ratios of parts were lower than $10 \%$. The cloud chart of thickness distribution was assessed and the results are shown in Fig.6. It could be seen from the simulation results that the serious wrinkle occurred in the flange section of part when the overflowing pressure of liquid chamber was $20 \mathrm{MPa}$. Distortion occurred and the phenomenon of wrinkle was serious when the pressure reached $30 \mathrm{MPa}$, while the thinning ratio of wall thickness was $9.76 \%$. However, the forming quality of part was much better when the pressure was $25 \mathrm{MPa}$. Depending on these results, the pressure of liquid chamber of $25 \mathrm{MPa}$ was selected and used.

1.3.2 Effect of blank holder gap on distribution of wall thickness

The blank holder gap or blank holder force, defined as one of key factors, determine whether the forming is successfully completed or not. Hence, the simulation about the effect of blank holder gap on the forming results was carried out. In this study, the blank holder gap took respectably sheet thickness of 1.02, 1.05, 1.08 and 1.1 times. The maximum pressure of liquid chamber was $25 \mathrm{MPa}$. The thinning ratios of the part are shown in Fig.7. It can be seen from the curve

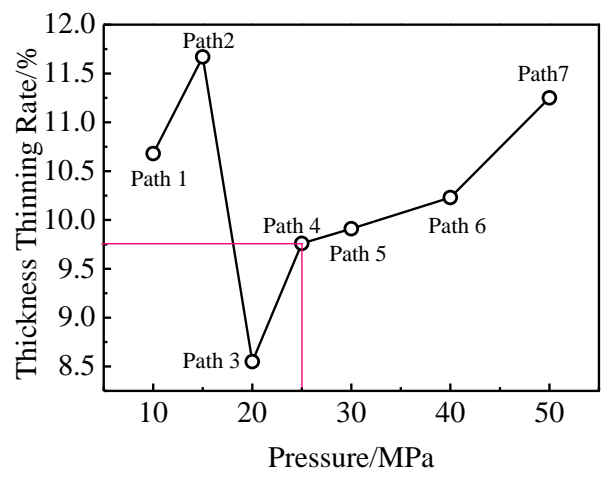

Fig.5 Thinning ratio of part's wall thickness at different pressures of liquid chamber

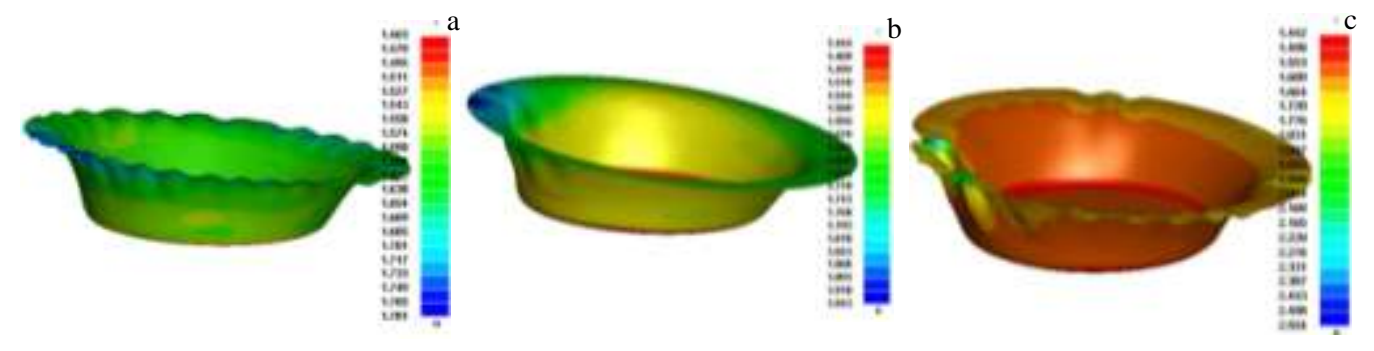

Fig.6 Distribution of part's wall thickness at different overflowing pressures: (a) $20 \mathrm{MPa}$, (b) $25 \mathrm{MPa}$, and (c) $30 \mathrm{MPa}$

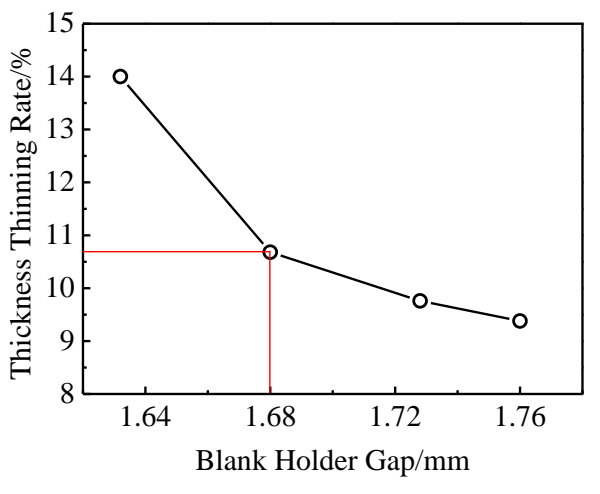

Fig.7 Effect of holder gap on the maximum thinning ratio diagram that the maximum thinning ratios for the part were $11.67 \%, 10.68 \%, 9.76 \%$ and $7.5 \%$, corresponding to different blank holder gaps. The thickness of the part increased with the blank holder gap increasing. When the blank holder gap was smaller, the mechanical stress between the sheet and the blank holder and the stress of the contacting surface of the die also increased. As a result, the thinning of sheet was serious since the flow of sheet was hampered caused by the high friction forces on the flange section of the sheet.

1.3.3 Effect of pre-bulging pressure on the minimum wall thickness

During the initial stage of the forming, pre-bulging pressure was required in the liquid chamber in order to make the sheet 
fit closely with the punch. However, the parts studied in this paper had problems, such as the edge of flange being not parallel to the bottom and presence of a taper on the side wall etc. In the initial phase of forming, the sheet was not in contact with the punch completely and only contacted locally. After the punch moved downwards with a certain distance, the sheet was fully in contact with the bottom of punch, as shown in Fig.8. Therefore, an appropriate initial pre-bulging pressure needs to be established to minimize the defects of sheet wrinkle and fracture during the initial forming stage.

Fig.9 shows the overall loading routes after the pre-bulging pressure. The loading route 1 is that a pressure of $0 \mathrm{MPa}$ was applied during time interval of $0 \sim 0.01 \mathrm{~s}$, the pressure in liquid chamber was increased linearly to $25 \mathrm{MPa}$ in the time interval of $0.01 \sim 0.03 \mathrm{~s}$, and the pressure of liquid chamber was kept at 25 $\mathrm{MPa}$ in the time interval of $0.03 \sim 0.055 \mathrm{~s}$. The loading route 2 is that a pressure of $2 \mathrm{MPa}$ was applied during the time interval of $0 \sim 0.01 \mathrm{~s}$, the pressure of liquid chamber was increased linearly to $25 \mathrm{MPa}$ in the time interval of $0.01 \sim 0.03 \mathrm{~s}$, and the pressure of liquid chamber was kept at $25 \mathrm{MPa}$ in the time interval $0.03 \sim 0.055 \mathrm{~s}$. The loading route 3 is that a pressure of $5 \mathrm{MPa}$ was applied in the time interval of $0 \sim 0.01 \mathrm{~s}$, the pressure of liquid chamber was increased linearly to $25 \mathrm{MPa}$ in the time interval of $0.01 \sim 0.03 \mathrm{~s}$, and the pressure of liquid chamber was kept at 25 $\mathrm{MPa}$ in the time interval of $0.03 \sim 0.055 \mathrm{~s}$.

The minimum values of wall thickness of the part obtained with different loading routes are shown in Fig.9. It can be seen that the thinning of part thickness is the minimum according to the loading route 2 ; in other words, the pre-bulging pressure is $2 \mathrm{MPa}$ and the overflowing pressure of liquid chamber is 25 $\mathrm{MPa}$. Therefore, it is possible to form a good-quality part with a relatively uniform wall thickness.

\section{Results and Analysis}

\subsection{Experiments on hydrodynamic deep drawing and forming of beveled and cylindrical parts}

An experiment on hydrodynamic deep drawing of 2198 Al-Li alloy sheet was carried out on the Hydraulic Press with capacity 100 Tons. The diameter of blank was $200 \mathrm{~mm}$ and the thickness of blank was $1.6 \mathrm{~mm}$. Both the fillet radii of punch and die were $10 \mathrm{~mm}$. The optimum forming technological parameters are obtained from the numerical simulation. The blank holder gap is 1.05 times of the sheet thickness, and the shape of blank holder gasket and the position of the sheet placement are obvious, as shown in Fig.10. Besides, the pre-bulging pressure is $2 \mathrm{MPa}$ and overflowing pressure of liquid chamber is $25 \mathrm{MPa}$. Before the experiment, grease was employed to stick the polyethylene film on both sides of the sheet to reduce the friction. Then, the sheet was placed in the gasket of blank holder. Since the gasket of blank holder has been used to produce the blank holder gap, the thickness of gasket of blank holder was 1.05 times of the sheet thickness. As soon as the punch pressed the sheet downwards with a movement of $5 \mathrm{~mm}$, the loading of pre-bulging pressure was started. The downward speed of the punch was $20 \mathrm{~mm} / \mathrm{s}$ and stroke of the punch were $20 \mathrm{~mm} / \mathrm{s}$. Meanwhile, the liquid chamber was filled with hydraulic oil, and the sheet was lifted upwards under the pressure. The oil overflowed from the liquid chamber, creating the lubricating effect. Furthermore, the blank holder pressed the sheet tightly to produce a sealing effect. Thereby, the pre-bulging of the sheet was carried

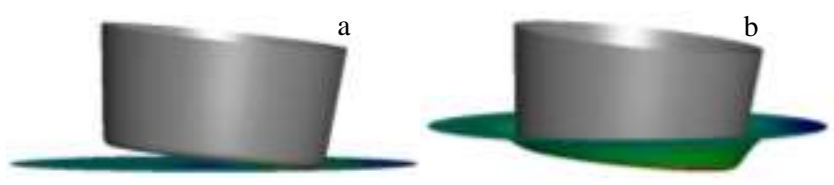

Fig.8 Contact between the punch and sheet during the forming process: (a) partly contact and (b) fully contact

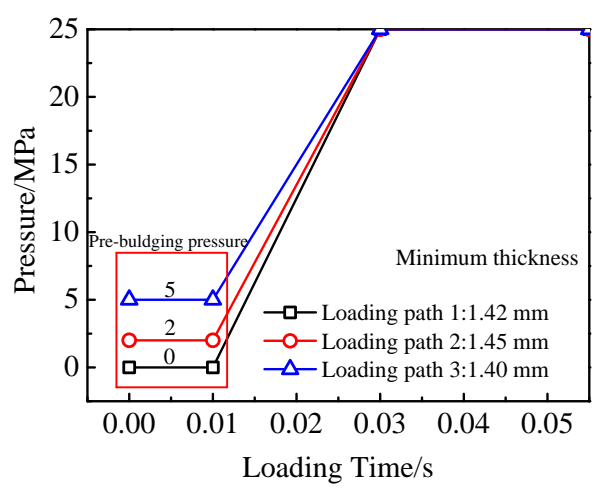

Fig.9 Loading routes under different reverse expanding pressures
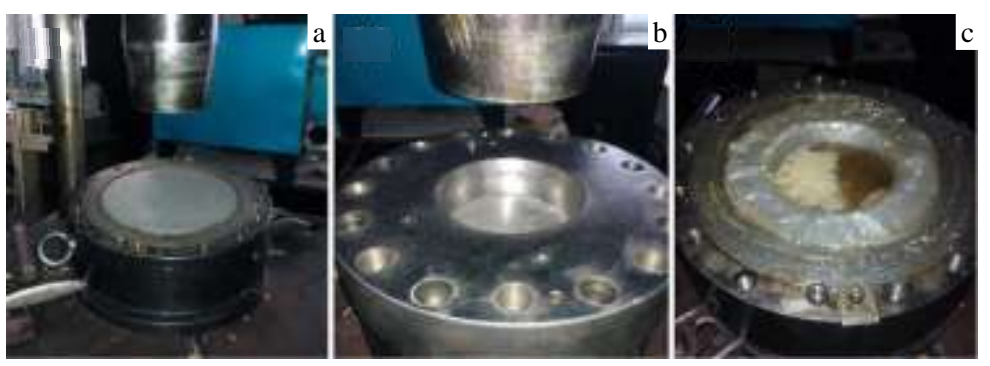

Fig.10 Shape of blank holder gasket and the position of the sheet placement: (a) sheet blank, (b) before hydrodynamic deep drawing, and (c) after hydrodynamic deep drawing 
through. The maximum pressure of liquid chamber was controlled by means of the overflow valve.

Fig.11 shows the defect in part obtained from the HDD experiment. The failure mode was analyzed and the primary causes for failure were determined. During the process of HDD, the punch and the sheet contacted completely in the initial phase of the forming, and the side wall of punch was a taper segment. The local plastic deformation of the sheet also occurred during this stage of forming. The frictional forces between the sheet and the fillet of the punch resulted in the appearance of cracks in the subsequent drawing process. In comparison to the numerical simulation results, the deformation occurring at this position was large and the deformation reached to $29.6 \%$. Meanwhile, it was found that there were obvious friction scratches around the cracks, which indicated that strong abrasions occurred between the sheet and the die during the forming process.

Fig.12 shows the qualified 2198-T3 aluminum lithium alloy part formed by the hydrodynamic deep drawing and forming method. The forming part obtained by the numerical simulation method is shown in Fig.12b.

The numerical simulation results of side wall thickness along the line at the highest point of part and the actual thickness distribution of part under test were compared for determining the accuracy of the former. The result is shown in Fig.13 after extracting the values of thicknesses along the section line of A-A. It can be seen that the distribution of thicknesses in the numerical simulation are consistent with the trends of the experimental results. The most serious thinning areas are all located at the positions of fillet radii of the button. The thickness value of this experimental measurement at this position was $1.42 \mathrm{~mm}$, and the simulated value was $1.47 \mathrm{~mm}$. The actual hydroforming was $11.25 \%$. However, the maximum thinning ratio of part in the numerical simulation was $8.125 \%$. The dimensions and the surface quality of the formed part were better, which proved that the numerical simulation results are consistent with the experimental results.

\subsection{Microstructure analysis}

The beveled and cylindrical part obtained on hydrodynamic deep drawing was evaluated by the microstructure analysis. Three samples were taken from the die radius, the cylinder wall and the punch radius, compared with the original blank. The microstructures are shown in Fig.14. The grains of original blank are long strips because of rolling and the microscopic grain structure of the major deformation zones on hydrodynamic deep drawing is clearly stretched. The grain size remained relatively stable during the drawing and the grain distribution was uniform, indicating that the actual molding parts possessed good microstructure. It could be seen that grains at die radius were elongated seriously, and the

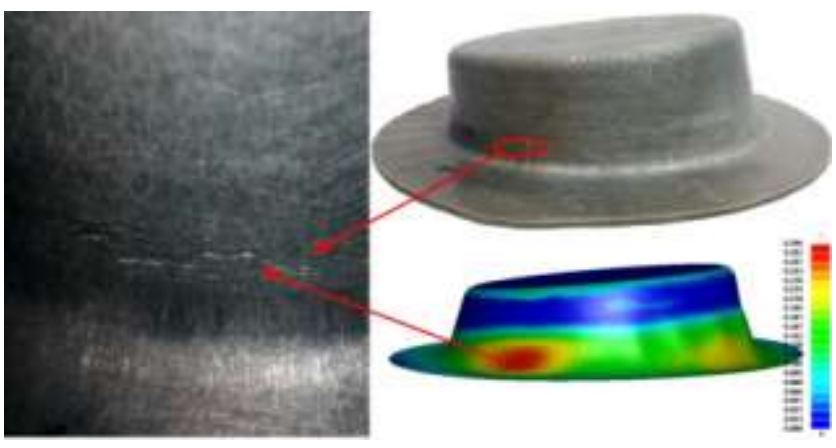

Fig.11 Occurrence of cracks around the round radius of 2198 aluminum lithium alloy part during hydroforming

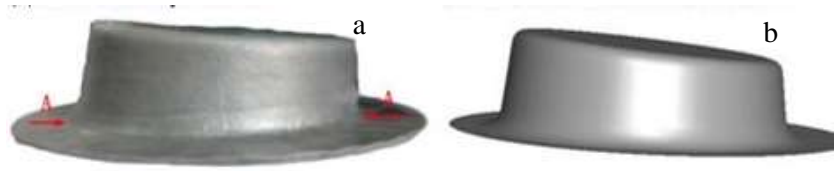

Fig.12 Comparison of the parts from actual hydroforming numerical simulation: (a) part from experiments and (b) part from numerical simulation

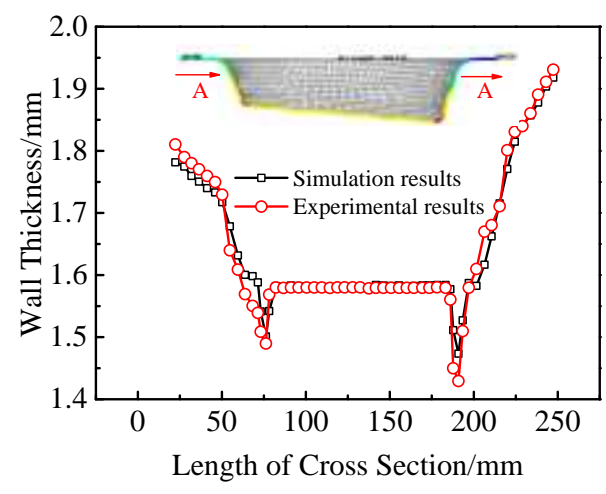

Fig.13 Distribution of wall thickness of the part along the sectional line
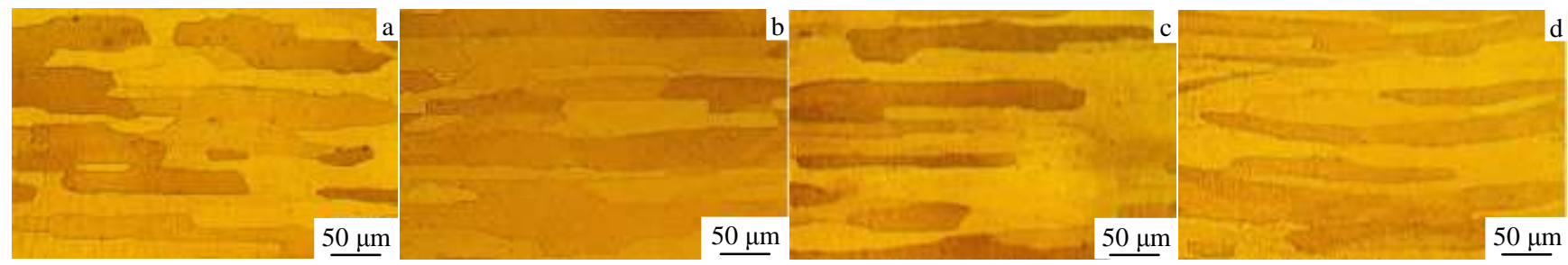

Fig.14 Microstructures obtained at different parts: (a) original billet, (b) cylinder wall, (c) punch radius, and (d) die radius 
grains were bent due to strong abrasions between the sheet and the die during the forming process. The cracks maybe occur at the die radius owing to the deformation reaching the forming limit, as shown in Fig.14.

\section{Conclusions}

1) During the hydrodynamic deep drawing processes of aluminum lithium alloy 2198, the severe wrinkle occurs when the overflowing pressure of liquid chamber is low or high. To avoid wrinkle and obtain smaller thinning ratio of part's wall thickness and better forming quality, the pressure inside the liquid chamber of $25 \mathrm{MPa}$ is recommended.

2) When the blank holder gap is smaller, the mechanical stress between the sheet and the blank holder, or the contacting surface of die increases. As a result, the thinning of sheet is serious because the flow of sheet is hampered owing to the high friction forces on the flange section of the sheet.

3) To obtain the minimum thinning ratio of pipe wall thickness and uniform wall thickness, pre-bulging pressure of $2 \mathrm{MPa}$ and overflowing pressure of $25 \mathrm{MPa}$ are advisable.

\section{References}

1 Liu B, Peng C Q, Wang R C et al. The Chinese Journal of Nonferrous Metals[J], 2010, 20(9): 1705 (in Chinese)

2 Rioja R J, Liu J. Metallurgical and Materials Transactions A[J], 2012, 43(9): 3325

3 Lequeu P, Lassince P, Warner T. Advanced Materials and Processes[J], 2007, 165(7): 41

4 Deschamps A, Decreus B, De Geuser F et al. Acta Materialia[J], 2013, 61(11): 4010

5 Steglich D, Wafai H, Brocks W. International Journal of Damage Mechanics[J], 2010, 19(2): 131

6 Halkaci H S, Turkoz M, Dilmec M. Journal of Materials Processing Technology[J], 2014, 214(8): 1638

7 Kang B S, Ku T W. The International Journal of Advanced Manufacturing Technology[J], 2011, 53(1-4): 131

8 Dhumal A T, Narayanan R G, Kumar G S. International Journal of Modeling, Identification and Control[J], 2012, 15(3): 164

9 Hassan M A, Ahmed K I E, Takakura N. Journal of Materials Processing Technology[J], 2012, 212(1): 295

10 Liu J, Tan M J, Jarfors A E W et al. Materials \& Design[J], 2010, 31: S66

11 Paulsen F, Welo T. International Journal of Mechanical Sciences[J], 2001, 43(1): 109

\title{
2198 铝锂合金充液拉深成形模拟及试验
}

\author{
郭训忠 ${ }^{1}$, 王刘安 ${ }^{1}$, 凌 娟 $^{2}$, 马福业 ${ }^{1}$, 陶 杰 $^{1}$, 徐 勇 $^{3}$, 靳 凯 ${ }^{4}$, 王会廷 ${ }^{5}$ \\ (1. 南京航空航天大学, 江苏 南京 211106) \\ (2. 江苏省特种设备安全监督检测研究院, 江苏 南京 210036) \\ (3. 中国科学院金属研究所 辽宁 沈阳 110016) \\ (4. 西江大学, 韩国 首尔 121-742) \\ (5. 安徽工业大学, 安徽 马鞍山 243002)
}

\begin{abstract}
摘 要: 通过有限元模拟 2198 铝锂合金斜面筒形件的充液拉深过程, 结合试验对其塑性变形规律进行研究。研究结果表明：在板料充 液拉深过程中, 合适的液室溢流压力直接影响充液拉深; 压边间隙影响零件的减薄率; 合适的预胀压力可减小零件厚度减薄率，能够获 得壁厚相对均匀, 成形质量较好的零件。
\end{abstract}

关键词: A12198; 充液拉深; 有限元模拟; 试验成形

作者简介: 郭训忠, 男, 1981 年生, 博士, 副教授, 南京航空航天大学材料科学与技术学院, 江苏 南京 211106, 电话: 025-52112911, E-mail: guoxunzhong@nuaa.edu.cn 